\title{
Household livelihoods and conflict with wildlife in community-based conservation areas across northern Tanzania
}

\author{
Jonathan Salerno, Monique Borgerhoff Mulder, Mark N. Grote \\ Margherita Ghiselli and Craig Packer
}

\begin{abstract}
Conservation strategies to protect biodiversity and support household livelihoods face numerous challenges. Across the tropics, efforts focus on balancing trade-offs in local communities near the borders of protected areas. Devolving rights and control over certain resources to communities is increasingly considered necessary, but decades of attempts have yielded limited success and few lessons on how such interventions could be successful in improving livelihoods. We investigated a key feature of household wellbeing, the experience of food insecurity, in villages across Tanzania's northern wildlife tourist circuit. Using a sample of 2,499 primarily livestock-keeping households we compared food insecurity in villages participating in the country's principal community-based conservation strategy with nearby control areas. We tested whether communitybased projects could offset the central costs experienced by households near strictly protected areas (i.e. frequent human-wildlife conflict and restricted access to resources). We found substantial heterogeneity in outcomes associated with the presence of community-based conservation projects across multiple project sites. Although households in project villages experienced more frequent conflict with wildlife and received few provisioned benefits, there is evidence that these households may have been buffered to some degree against negative effects of wildlife conflict. We interpret our results in light of qualitative institutional factors that may explain various project outcomes. Tanzania, like many areas of conservation importance, contains threatened biodiversity alongside areas of extreme poverty. Our analyses highlight the need to examine more precisely the complex and locally specific mechanisms by which interventions do or do not benefit wildlife and local communities.
\end{abstract}

Jonathan Salerno (Corresponding author) Graduate Group in Ecology, University of California, Davis, One Shields Avenue, Davis, CA 95616, USA E-mail jdsalerno@ucdavis.edu

Monique Borgerhoff Mulder and Mark N. Grote Department of Anthropology, University of California, Davis, USA

Marghertta Ghiselli Division of Epidemiology and Community Health, University of Minnesota, Minneapolis, USA

Craig Packer Department of Ecology, Evolution \& Behavior, University of Minnesota, St. Paul, USA

Received ${ }_{13}$ September 2014. Revision requested 7 November 2014. Accepted 4 March 2015. First published online 10 September 2015.
Keywords Conservation management, food security, protected areas, Wildlife Management Areas, wildlife tourism

To view supplementary material for this article, please visit http://dx.doi.org/10.1017/So030605315000393

\section{Introduction}

T $\mathrm{n}$ tropical regions trade-offs between human well-being 1 and biodiversity conservation occur most directly in rural communities near the borders of protected areas. Households in these communities incur costs through the loss of land and access to resources, which can limit livelihood opportunities (West et al., 2006; Coad et al., 2008), as well as from direct conflict with wildlife (Hulme \& Murphree, 2001; Thirgood et al., 2005; Dickman et al., 2011). Community-based conservation, or the devolution of management and user resource rights to local communities, is promoted as a conservation tool to balance human well-being with biodiversity protection (Borgerhoff Mulder \& Coppolillo, 2005). Since their inception the performance of community-based conservation and similar strategies has been debated, and policies in favour of such strategies have faced opposition from conservation biologists and social scientists alike (Naughton-Treves et al., 2005; Roe, 2008). Evaluations have highlighted numerous shortcomings: projects struggle to generate sufficient longterm revenue and maintain equitable access to economic benefits (Kiss, 2004; Garnett et al., 2007), to overcome assumptions regarding community institutions (Agrawal \& Gibson, 1999) and state-level governance (Nelson, 2010), to ensure de facto control of resources at the village level along with adequate capacity support (Tallis et al., 2008), and to achieve ecological goals (Salafsky et al., 2001). Nevertheless, quantitative evidence suggests positive social and ecological outcomes can result from conservation efforts around protected areas (McNally et al., 2011; Ferraro \& Hanauer, 2014b) and from community-based conservation projects (Tallis et al., 2008; Brooks et al., 2012).

Accordingly, it is important to consider comparative quantitative evidence in the evaluation of projects that engage in conservation efforts around protected areas (Pullin et al., 2013). Given the variation in outcomes demonstrated through evaluations of community-based conservation, one 
question remains central: are community-based strategies successful in achieving their broader goals? Decades of initiatives have yielded conflicting results, which can be attributed to multiple factors. The majority of evidence regarding project success is drawn from single cases over restricted time periods, rendering generalization problematic (Brooks et al., 2006). Desired project outcomes are rarely defined explicitly, which creates difficulty for evaluators in selecting appropriate measures of success (Agrawal \& Redford, 2006), particularly when trade-offs are common (e.g. between ecological and economic goals; Brooks et al., 2012). Furthermore, insufficient attention is directed towards the intervening mechanisms by which projects and initiatives ultimately affect well-being and biodiversity (Ferraro \& Hanauer, 2014b). Given the poor state of the evaluation literature in these respects (Miteva et al., 2012; Bottrill et al., 2014), and given that community-based conservation success necessarily depends on some level of community engagement affecting household livelihoods, we chose to investigate an outcome that directly affects wellbeing: household food insecurity.

Wildlife management areas, the dominant model of community-based conservation in Tanzania, were developed to improve livelihoods in communities living near strictly protected areas and in close proximity to wildlife. The model, common throughout southern Africa, was designed following the much-acclaimed CAMPFIRE and ADMADE programmes in Zimbabwe and Zambia (Leader-Williams et al., 1996). Similar national-scale policies are premised on decentralized control of resources, placing rights and authority over land and wildlife in the hands of local governments to incentivize effective local management and often to generate tourism revenue (Igoe \& Croucher, 2007). However, communities are rarely given the rights and capacity support to manage resources independently (Nelson, 2010). Instead, community-based conservation policy is essentially a financial bargain between national governments and communities, where a fraction of state tourism revenue is directed towards communities in exchange for local lands being designated for conservation.

In Tanzania and elsewhere, implicit in the bargain is that (1) potential for economic gain motivates local rule enforcement and conservation behaviour (e.g. poaching patrols, adhering to land use restrictions), (2) households receive direct or indirect benefits (e.g. cash, meat, access to schools, improved infrastructure), and (3) benefits outweigh the individual costs of human-wildlife conflict and loss of access to resources in the areas designated for wildlife protection (Mackenzie, 2012; Tetra Tech \& Maliasili Initiatives, 2013).

The challenge in evaluating community-based conservation policies is therefore to test the performance of this bargain. Can economic instruments administered at the state level benefit household livelihoods and promote local wildlife management? In the absence of explicitly defined goals and outcomes (Brooks et al., 2006; Garnett et al., 2007) we evaluate the performance of wildlife management areas in terms of household food insecurity. This is a critical measure of well-being in Tanzania and in similar systems (see below). We pay particular attention to the role of wildlife management areas in potentially offsetting the costs of human-wildlife conflict; we propose that serving this function is important because of the necessity for households to tolerate interactions with wildlife for the wildlife management area programme to succeed. We conduct our evaluation across Tanzania's northern tourist circuit, using a household sample that includes multiple wildlife management areas alongside control areas. This approach addresses many of the problems of existing evaluations, and we target our findings towards the ongoing adaptive management of community-based conservation in Tanzania and similar strategies throughout the tropics.

\section{Community conservation in Tanzania and the importance of food security}

Across much of Tanzania and other dryland areas of southern Africa, rural livelihoods are based primarily on small farm and livestock holdings, with decision-making centred around avoiding chronic, seasonal and stochastic food shortages inherent in pastoral production and dryland agriculture (Ellis \& Mdoe, 2003; Doss et al., 2008). Food insecurity in this region is widespread, stemming from numerous social and ecological factors, and the effects on children's health in particular have significant long-term consequences (Lawson et al., 2014). Flexible livelihood strategies, allowing households to manage mixed-asset holdings of livestock and/or crops, can be effective at reducing food insecurity (Hadley et al., 2007). However, restrictions on resource use and mobility imposed by the authorities of strictly protected areas in Tanzania's northern tourist circuit limit these strategies, and livelihoods are further strained by population pressure and environmental variability (Baird \& Leslie, 2013; Goldman \& Riosmena, 2013; Salerno et al., 2014).

In addition, conflicts with wildlife near these protected areas impose livelihood costs and contribute to household food insecurity. Attacks by predators on people (Packer et al., 2005) and livestock (Holmern et al., 2007; Røskaft et al., 2013), as well as crop depredation (Gillingham \& Lee, 2003; Kaswamila et al., 2007), are frequent. Such conflicts inflict direct economic losses on livestock keepers and farmers, in addition to the opportunity costs of labour devoted to guarding herds and fields. Furthermore, there are direct links between livestock assets, livestock losses to predators, and household resilience, demonstrated through short-term food insecurity and long-term child health outcomes (Hoddinott \& Kinsey, 2001; Barua et al., 2013). 
The performance of wildlife management areas in Tanzania has yet to be evaluated in terms of an underlying measure of household well-being, including the state of food insecurity. Research suggests that wildlife management areas experience problems common among communitybased conservation initiatives, such as persistent humanwildlife conflict (e.g. Gillingham \& Lee, 2003), difficulty distributing direct economic benefits within participating communities (e.g. Bamford et al., 2014), and barriers to representative local governance and gaining de facto control over resources (e.g. Benjaminsen et al., 2013). The majority of studies draw on single cases and varying, often qualitative indicators of success. Furthermore, a more comprehensive multisite report using quantitative measures demonstrated increased household assets over a 10-year period, along with signs of strengthened local governance (Tetra Tech \& Maliasili Initiatives, 2013), yet no controls were implemented to account for underlying changes.

Outcomes of wildlife management areas are likely to be variable, but the variability must be quantified in meaningful ways to evaluate the policy as a whole. A systematic evaluation is needed, as wildlife management areas hold significant potential given the formal legislation of the rights to control the land (Sulle et al., 2011; Government of Tanzania, 2012), the significant economic value of wildlife for tourism (Sekar et al., 2014), the enabling environment of donor support, and the suggested gains in household wealth and village institutional capacity (Tetra Tech \& Maliasili Initiatives, 2013).

We used data from rural villages both within and outside wildlife management areas in Tanzania to ask a critical question regarding the performance of the current community-based conservation strategy: Is there an association between household food insecurity and wildlife management area status? Given the context of vulnerability across our system, we explored the association between food insecurity and human-wildlife conflict and asked whether wildlife management areas may lessen the negative effects of human-wildlife conflict, and whether certain livelihood activities can better support households that are vulnerable to food insecurity in the presence or absence of wildlife management area status. We assessed these research questions using data from 2,499 rural households and Bayesian multilevel statistical models.

\section{Study area}

The study was conducted within the protected area landscape at the centre of Tanzania's tourism economy (Sachedina \& Nelson, 2010; Fig. 1). Significant areas of savannah and mixed woodlands are protected as national parks (prohibiting settlement, access and resource use by local people), game reserves (allowing licensed trophy hunting by non-local users) and the Ngorongoro Conservation Area (permitting limited settlement and pastoralist activities) (IUCN \& UNEP, 2010). Wildlife populations move within and between the protected areas according to variable seasonal rainfall patterns. Rural households of $>60$ ethnic groups (predominantly Maasai, Sukuma and Rangi) rely primarily on small farm and/or livestock holdings (Lawson et al., 2014), although pastoralists are increasingly shifting to more crop-based livelihoods (Baird \& Leslie, 2013). Ecological and economic value along with ethnic diversity and widespread rural poverty motivate efforts by government and NGOs to balance trade-offs, thereby providing an ideal test case for evaluation of community-based conservation.

\section{Methods}

Household data were collected between mid 2009 and mid 2011 in 56 rural villages as part of the Whole Village Project, a collaborative initiative of Savannas Forever Tanzania and the University of Minnesota (Borgerhoff Mulder et al., 2010; Lawson et al., 2014). The sampling of villages was based in part on the priorities of development agency partners and the permission of government officials, with attention given to representativeness across environmental and ethnic factors. Institutional assessments were conducted in each village through interviews with village leaders and randomly selected focus groups. In addition to qualitative information these activities yielded village-level variables describing the perceived effectiveness of village governments and relevant stakeholders (e.g. wildlife management areas, active NGOs; Supplementary Material 1).

We used a subset of 40 villages adjacent to protected areas to evaluate the effectiveness of wildlife management area interventions relative to a control group (Fig. 1). Adjacency was defined as within $45 \mathrm{~km}$ of a strictly protected area border, based on the furthest distance between a participating village within a wildlife management area and a protected area border. At the time of the study 13 of the 40 villages were participating in one of four wildlife management areas: Burunge, Enduimet, Makame and Makao (Supplementary Table S1). Participating villages contribute land to a jointly controlled wildlife management area, which is managed by an Authorized Association comprising representatives from each village. Although participation is voluntary at the village level, all resident households are considered to be part of the wildlife management area once the village joins the Authorized Association (Supplementary Material 1).

In each village a random sample of c. 60-70 households was selected from village administrative rosters. Tanzanian field teams administered structured questionnaires to household heads in Kiswahili or the local language. Given 


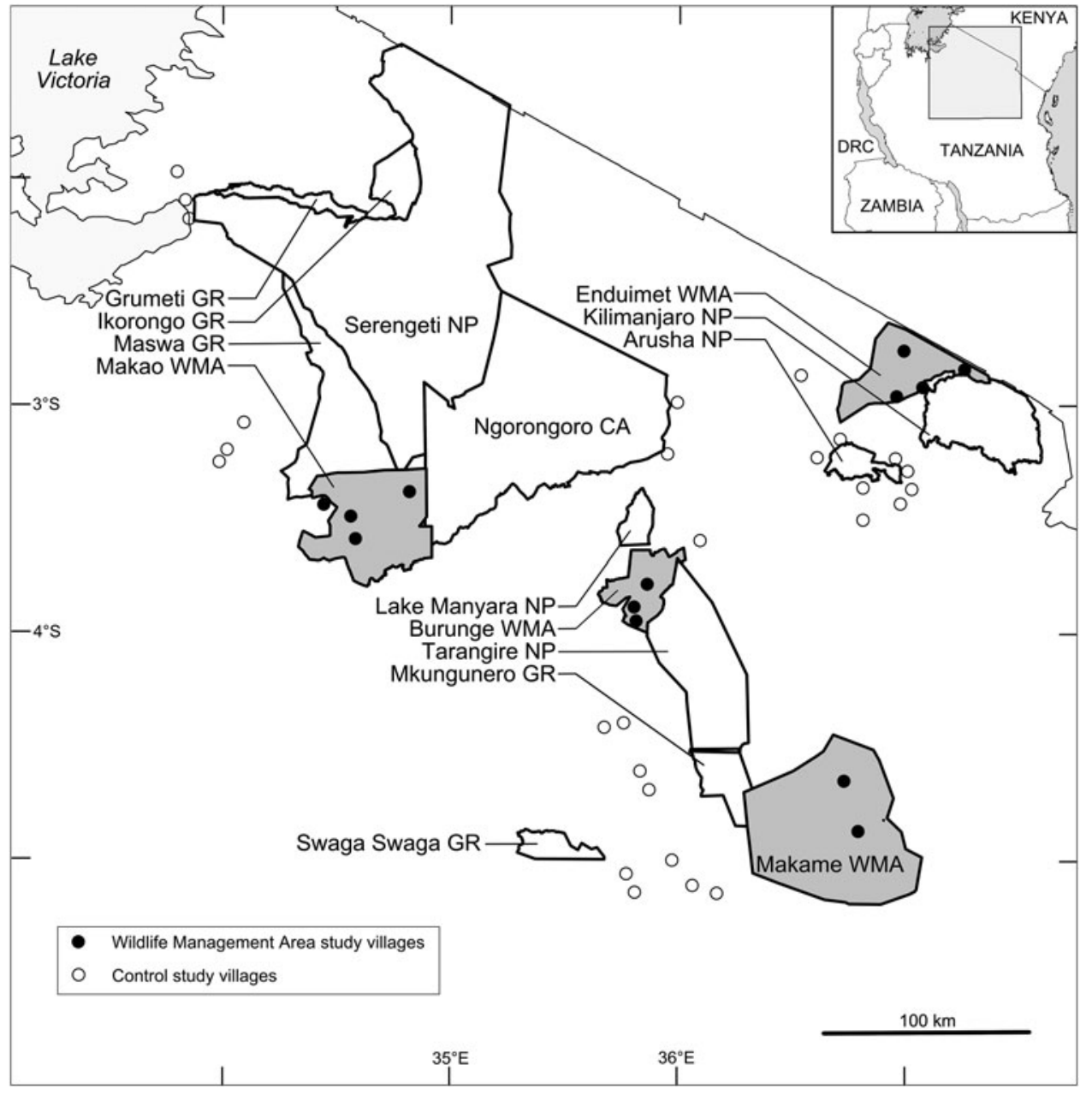

FIG. 1 The protected area landscape of northern Tanzania: Makao, Burunge, Enduimet and Makame wildlife management areas (WMA), national parks (NP), game reserves (GR) and conservation area (CA), with 40 adjacent study villages. the salience of a reliable food supply to households in the arid and semi-arid zones of East Africa, we measured household well-being in terms of food insecurity, using the Household Food Insecurity Access Scale (Coates et al., 2007). Each household was assigned to one of four categories, food secure, mildly food insecure, moderately food insecure or severely food insecure, based on responses to a series of food-related questions. We treated food insecurity as an ordered categorical outcome variable. Human-wildlife conflict was recorded as a binary variable indicating whether or not a household had lost specific types of livestock and/or crops in the previous 12 months; crop loss frequency was not recorded in all villages, and therefore we report this variable for descriptive purposes only and omit it from our statistical models and main conclusions. Household productive livelihood assets were measured as the number of acres cultivated and number of livestock owned (cattle, sheep/goats and poultry). Models include a set of household control variables (e.g. construction material of home, bicycles and mobile phones owned) to account for differences in wealth as revealed through these commonly purchased items. The resulting database characterized the well-being and livelihoods of 2,499 households adjacent to protected areas (Supplementary Material 2).

The survey tools and methodology were approved by the University of Minnesota ethics board and collaborating Tanzanian research institutes.

\section{Analytical approach}

We considered descriptive measures of our household sample and then fitted multilevel regression models to investigate the relationship between food insecurity and the focal predictors used to evaluate our research questions: wildlife management area status, human-wildlife conflict, and livelihood strategy (i.e. variable reliance on livestock vs agricultural productive assets).

Because of the multilevel structure of the data (i.e. households clustered within villages, villages clustered within wildlife management areas) we included varying (random) intercepts for villages and wildlife management areas in all models. These intercepts capture contextual effects shared within villages and wildlife management areas that could 
make household-level food insecurity measures nonindependent (Supplementary Material 3).

We fitted proportional-odds ordered logistic regression models using Markov-chain Monte Carlo methods (Plummer, 2003). In each model a linear equation $\tau_{c}-\mu$ gave the log-odds that a household was at or below food insecurity level $c$, as a function of predictors and control variables. We began with a basic model for $\mu$ containing only varying intercepts, along with a fixed effect for wildlife management area status:

$$
\mu_{h, V, W}=A_{V}+B_{W}+\omega \chi_{h}
$$

where $A$ is the varying intercept effect for village $V, B$ is the varying intercept effect for wildlife management area $W$, and $\omega$ is the fixed effect of wildlife management area status, with the status of household $h$ indicated by the binary variable $\chi$. The same equation $\mu$ applies at all levels $c$ of the ordered outcome and is best understood as predicting more or less food insecurity (broadly speaking) as the effects on the right-hand side change in sign and magnitude (McCullagh \& Nelder, 1989, section 5.2).

To the basic model we added predictors derived from our research questions: human-wildlife conflict, a wildlife management area-specific adjustment to the human-wildlife conflict effect, and productive livelihood assets. The adjustment predictors were specified as binary variables for three types of livestock loss, along with interaction terms for each type of loss with wildlife management area status. The hypothesis that harmful effects of livestock loss are reduced by participation in a wildlife management area would be supported if model coefficients for livestock loss were positive (predicting greater food insecurity after a loss) but those for the interactions were negative (reversing the effect of loss, perhaps only partially). In addition to these predictors we added household-level control covariates to account for differences in wealth accumulation. All models, with the exception of the basic model, included household-level control covariates (Supplementary Material 2 \& 3).

Questions regarding food insecurity, human-wildlife conflict and mitigating effects of wildlife management areas, and productive livelihood assets can be investigated by examining the signs and magnitudes of relevant predictors, as well as by comparing models containing various combinations of these predictors (e.g. models containing only main effects vs those containing interactions). We used a posterior predictive criterion, the log-conditional predictive ordinate (logCPOs; Gelfand, 1996), to compare and rank models (Supplementary Material 3). The most complex models we considered included varying predictor effects (random slopes) for individual wildlife management areas. However, $\log \mathrm{CPO}$ ranked these models relatively lower than simpler models. Unless otherwise noted, the results presented are based on estimates from the topranked model, containing main effects and interactions for wildlife management area status and livestock loss, main effects for productive livelihood assets, and control covariates.

To describe the effects of focal predictors we present graphs showing how a change in each predictor changes the estimated odds of greater food insecurity. These changes are interpreted with respect to the indifference value of $1: 1$, indicating that a change in the predictor has little or no measurable effect. Uncertainty about the direction and magnitude of an effect is assessed from its posterior density (readily available via Markov-chain Monte Carlo samples). In the Discussion we interpret particular model results in light of our village-level institutional assessments to better understand contextual features that may inform management decisions for wildlife management areas.

\section{Results}

Food insecurity and participation in a wildlife management area

A higher proportion of households in villages that were participating in wildlife management areas were categorized as extremely food insecure, suffered from human-wildlife conflict (livestock and crop loss), and ranked lower on an index of household wealth, compared to control villages that were also adjacent to a protected area (Table 1; for comparisons between wildlife management areas see Supplementary Table S2). Although this observation suggests that households in wildlife management areas fare worse than those in control villages, more careful analysis is required to evaluate the association between household well-being and wildlife management area status.

Our analyses did not reveal consistent differences in food insecurity between households in wildlife management areas and those in control villages (Fig. 2). On average, households in wildlife management areas appear to be more food insecure (Fig. 2) but there is considerable variation between areas. We found more severe food insecurity in two of the four management areas (Enduimet and Makame; $43 \%$ of all households in a wildlife management area), whereas levels of food insecurity in the other two areas (Burunge and Makao) were similar to or lower than in control villages. The odds of severe food insecurity for a typical household in Makame were 5.67 times greater (95\% posterior credibility interval: 2.15-12.36) than for a similar household in a control village, whereas the odds for households in Burunge and Makao (Fig. 2) were similar to those of households in a control village. Wildlife management area status per se is therefore not a reliable predictor of food insecurity, but households in certain 
TABLE 1 Characteristics of the survey sample, based on wildlife management area status, with number of villages, number of households, proportion of households categorized as severely food insecure, mean household wealth index (based on ownership of items, excluding livestock and land; Supplementary Material 2), and proportion of households that experienced losses of livestock, cattle, sheep \& goats, poultry or crops as a result of human-wildlife conflict in the 12 months prior to the survey.

\begin{tabular}{|c|c|c|c|c|c|c|c|c|c|}
\hline & \multirow[b]{2}{*}{$\begin{array}{l}\text { No. of } \\
\text { villages }\end{array}$} & \multirow[b]{2}{*}{$\begin{array}{l}\text { No. of } \\
\text { households }\end{array}$} & \multirow{2}{*}{$\begin{array}{l}\text { Proportion } \\
\text { severely food } \\
\text { insecure }\end{array}$} & \multirow[b]{2}{*}{$\begin{array}{l}\text { Mean } \\
\text { wealth index }\end{array}$} & \multicolumn{5}{|c|}{$\begin{array}{l}\text { Proportion of households experiencing human-wildlife } \\
\text { conflict }\end{array}$} \\
\hline & & & & & $\begin{array}{l}\text { Livestock } \\
\text { loss }{ }^{1}\end{array}$ & $\begin{array}{l}\text { Cattle } \\
\text { loss }\end{array}$ & $\begin{array}{l}\text { Sheep/ } \\
\text { goat loss }\end{array}$ & $\begin{array}{l}\text { Loss of } \\
\text { poultry }\end{array}$ & $\begin{array}{l}\text { Loss of } \\
\text { crops }^{2}\end{array}$ \\
\hline $\begin{array}{l}\text { Non wildlife } \\
\text { management } \\
\text { area }\end{array}$ & 27 & 1723 & 0.44 & 1.50 & 0.34 & 0.02 & 0.10 & 0.27 & 0.18 \\
\hline $\begin{array}{l}\text { Wildlife man- } \\
\text { agement area }\end{array}$ & 13 & 776 & 0.55 & 0.98 & 0.54 & 0.19 & 0.33 & 0.28 & 0.47 \\
\hline
\end{tabular}

${ }^{1}$ Aggregate measure of cattle, sheep \& goats, and poultry

${ }^{2}$ Proportions based on a 27 -village subset of the sample

wildlife management areas may tend to be more or less food insecure.

\section{Wildlife conflict and participation in wildlife management areas}

Nineteen percent of sample households experienced one or more predation events on medium or large livestock in the 12 months preceding interviews, and the extent of these losses varied with wildlife management area status ( 38 and $10 \%$ of households in villages in wildlife management areas and control villages, respectively). This pattern was not discernible in households reporting predation on poultry. Our models supported an association between livestock loss and more severe food insecurity, while accounting for differences in livestock holdings and other factors (Fig. 3, dashed lines). Losses of cattle and sheep/goats were both associated with greater food insecurity, although there is more uncertainty regarding the deleterious effect of cattle loss, indicated by its relatively broad posterior density.

Despite these costs, results indicate that wildlife management area status was associated with a reduction in the harmful effects of livestock loss. Figure 3 shows the main effects of livestock losses (dashed lines) along with adjustments to those effects experienced by households in wildlife management areas (solid lines). Each plotted adjustment combines a main effect of loss with a wildlife management area interaction, leading to a modest reversal of the effect of loss. Losses of sheep and goats in households in control areas, for example, increased the odds of severe food insecurity by a factor of 1.69 on average ( $95 \%$ CI 1.13-2.45), whereas similar losses in households in wildlife management areas increased the odds by 1.44 (95\% CI 0.94-2.11). The latter interval includes the indifference value $1: 1$, suggesting the possibility that losses of sheep and goats in households in wildlife management areas may have little or no relationship to food insecurity. The wildlife management area adjustments for cattle and poultry show the same pattern but are more uncertain, although the density for cattle loss displays a substantial shift (Fig. 3). We attempted to differentiate the effects of individual wildlife management areas by allowing interactions to vary, but these more complex models ranked lower using logCPOs (model m2, Supplementary Material 3), and the wildlife management area-specific effects did not reveal between-area differences. These analyses were unable to detect specific mechanisms through which wildlife management areas could mitigate for livestock loss (see Discussion).

\section{Food insecurity and productive livelihood assets}

As could be expected, households with fewer productive livelihood assets (i.e. livestock and cultivated land) tended to be more food insecure (Supplementary Fig. S1). This relationship was consistent for sheep and goats, poultry, and cultivated land, whereas fewer cattle was not associated as consistently with more severe food insecurity. A lowerranked model including an interaction effect between productive livelihood assets and wildlife management area (model m3, Supplementary Material 3 ) suggested the effects of these assets did not differ between households in wildlife management areas and those in control areas. Thus, owning additional assets (particularly sheep/goats, poultry and cultivated land) is equally effective in protecting households against food insecurity whether or not a household is located in a wildlife management area. As with human-wildlife conflict and interaction effects noted above, a more complex model that allowed the effects of productive assets to vary by individual wildlife management area (model m4, Supplementary Material 3) ranked lower and produced estimates with more uncertainty. 


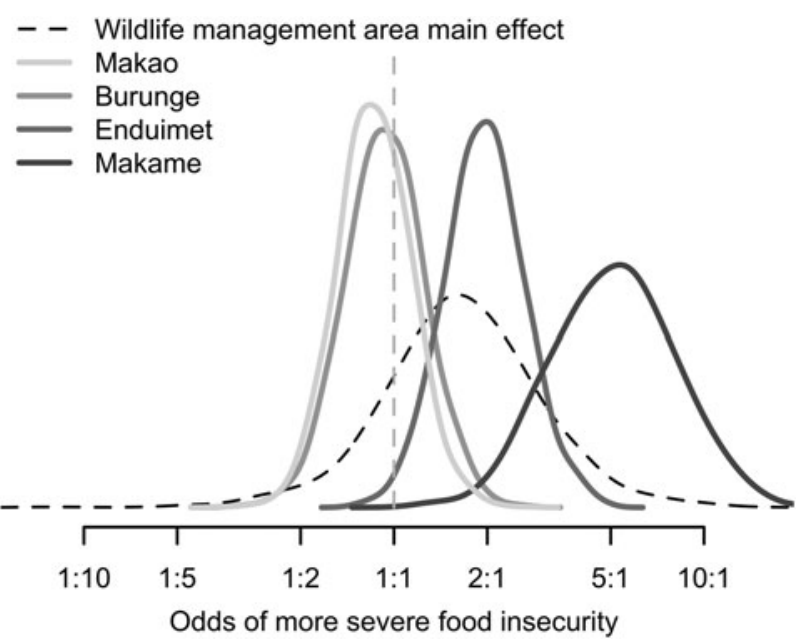

FIG. 2 Posterior densities of the effects of wildlife management areas on household food insecurity. The main effect estimate is shared by all households within a wildlife management area and may be interpreted as the mean effect on the odds of experiencing more severe food insecurity. Varying effects make unique adjustments for each wildlife management area; the estimates displayed for each wildlife management area are the additive results of the main effect plus these unique adjustments.

\section{Discussion}

Human-wildlife conflict is reported more commonly by households located in wildlife management areas than those in control areas, and a simple comparison suggests that households in wildlife management areas are generally more food insecure. However, our analysis across 40 villages found no strong evidence that wildlife management area status was associated with more severe food insecurity; most of the variation in food insecurity was between the individual wildlife management areas. We also report that the costly effects of human-wildlife conflict may be slightly lower in villages in wildlife management areas. Finally, although it is unsurprising that more livelihood assets predict lower household food insecurity, we show that these relationships are consistent between villages in wildlife management areas and those in control areas, as well as across individual wildlife management areas.

We first discuss specific results in the context of the Tanzanian wildlife management area experiment along with the implications for national conservation policy, integrating qualitative institutional assessments from each village into our quantitative findings. We then discuss the broader significance of our study.

\section{Are wildlife management areas working?}

Testing the economic arrangement of wildlife management area policy demonstrates that the strategy is not a universally effective community-based conservation solution, and it is likely that multiple factors contribute to the

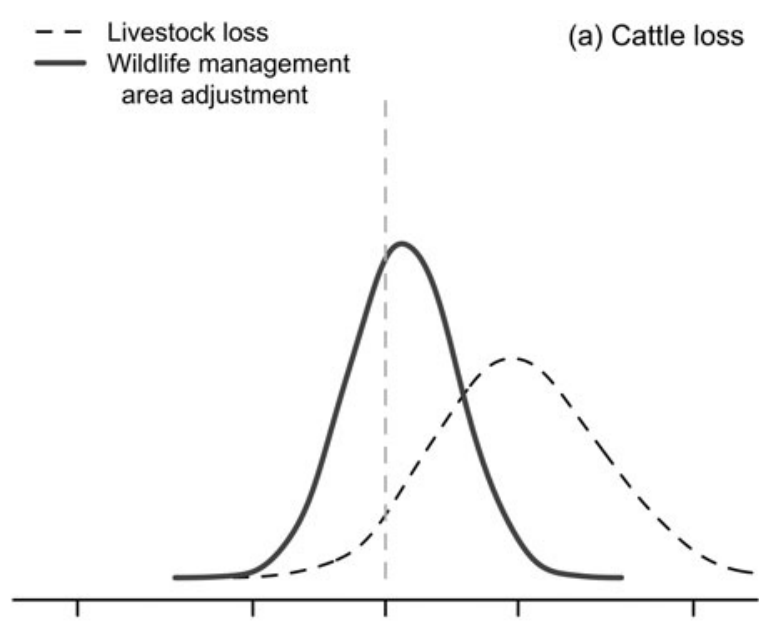

(b) Sheep/goat loss
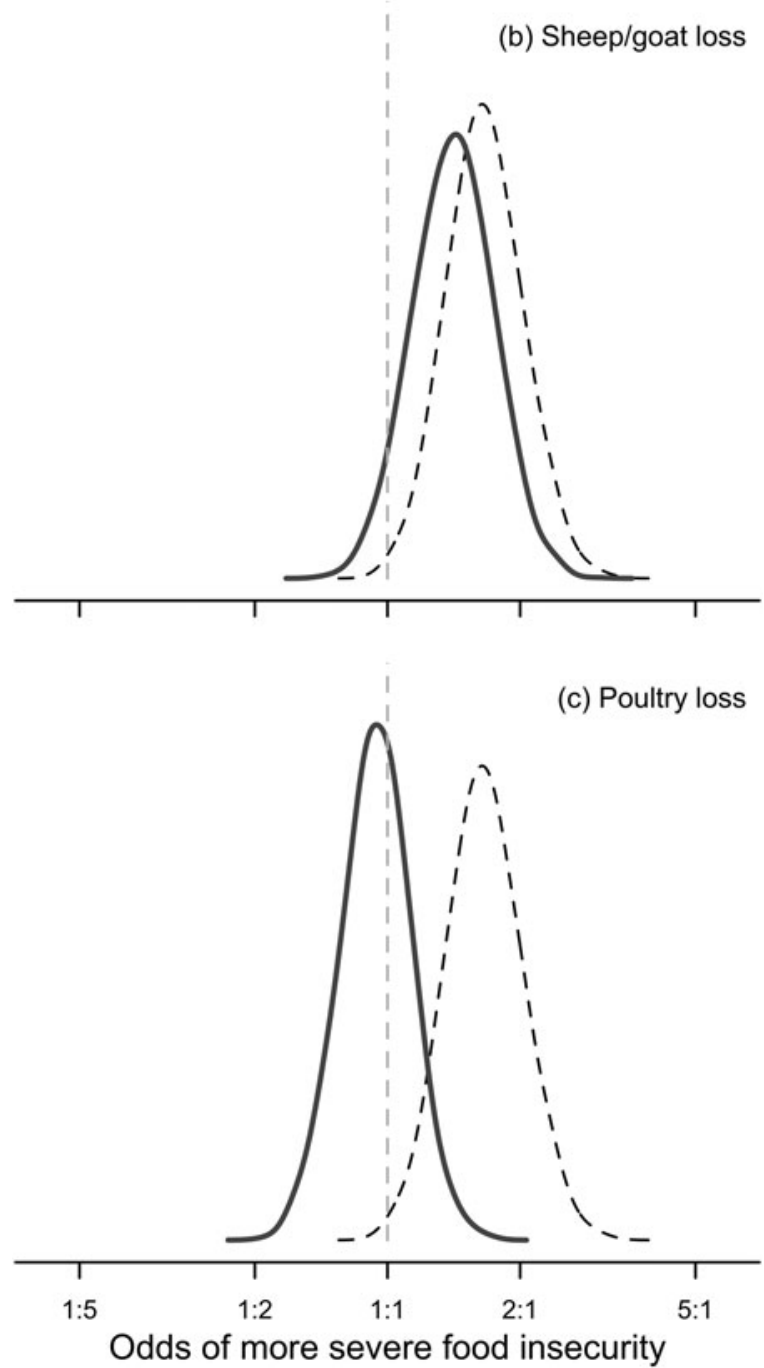

FIG. 3 Posterior densities of the effects of human-wildlife conflict on household food insecurity. Main effects of livestock loss (dashed lines) are shared by all households losing (a) cattle, (b) sheep or goats, and (c) poultry to wildlife. Model coefficients adjust for households that also participate in a wildlife management area, and are plotted as the additive result of the main effect of livestock loss and the wildlife management area interaction effect (solid lines). 
diversity of observed outcomes. We show that two of the wildlife management areas studied may support household well-being but households in the remaining two are particularly food insecure. This variation in effectiveness between wildlife management areas is most likely a result of institutional differences at the wildlife management area level, which we observed after controlling for other sources of variation between households (e.g. wealth) and between villages (e.g. social and ecological context, Supplementary Material 3; Goldman \& Riosmena, 2013; Lawson et al., 2014). Multiple factors contribute to the ability of the Authorized Associations governing wildlife management areas to meet programmatic and institutional challenges. These include protecting wildlife and habitat, attracting tourism companies and negotiating contracts (increasingly difficult for remote, dry and less biodiverse areas), collecting earned revenue from the state, distributing revenue to participating villages, and providing direct payments and adequate farming and grazing land to households. Furthermore, their capacity is affected by the varying levels of reliable support from donor organizations and agencies (Tetra Tech \& Maliasili Initiatives, 2013). These challenges are compounded by frequent incidents of human-wildlife conflict.

Because of the significant costs wildlife can impose on households, we explored associations between food insecurity and human-wildlife conflict and found suggestive evidence that the costs of losing livestock may be slightly lower in wildlife management areas. The interaction effect, although weak and imprecise, is evident when averaged across all wildlife management areas in the sample, and is consistent for various types of livestock lost. Evidence for such a mitigating effect is important, particularly if it is widespread, because the success of wildlife management areas depends on the presence of large wildlife populations to attract tourism revenue, but more wildlife leads to greater losses of livestock and crops, and ensuing food insecurity (Kaswamila et al., 2007). Identifying where such mechanisms exist will be an essential step in understanding which features of the intervention are effective and which are not.

We can only speculate as to the underlying effects responsible for food security outcomes and the observed reduction in the costs of human-wildlife conflict in wildlife management areas. Implicit in the wildlife management area bargain is that state-level revenues will, through various assumed pathways, positively affect residents. Wildlife management areas provide tangible benefits, such as the construction of health centres, schools and wells, implemented through the Authorized Associations, and most participating households recognize these gains (Tetra Tech \& Maliasili Initiatives, 2013). Perhaps, as suggested by Baird (2014), development initiatives may be concentrated in and around protected area networks, such that external organizations and funders preferentially direct resources near wildlife management areas. Such forms of rural development affect household health but our data are inadequate to test a causal link between development and food security.

Less direct benefits of wildlife management area establishment may emerge as a consequence of direct engagement with the policy process, and such institutional developments may distinguish wildlife management area villages from other villages that face similar challenges. The authorization requirements include the establishment of village land-use plans that designate areas for wildlife along with village forests and pastures (Sulle et al., 2011). Well-managed resource areas benefit households, and villages typically receive support from external organizations working with the wildlife management area Authorized Associations, although we do not have the data to address these claims directly. External donor support may strengthen the capacity of local governments (e.g. Persha \& Andersson, 2014), and the aforementioned multisite report (Tetra Tech \& Maliasili Initiatives, 2013) identifies small but tangible gains in the management capacity of wildlife management area village governments and shows that residents increasingly hold their leaders accountable. It is noteworthy, however, that the negotiation of rights to village lands and wildlife can also result in the appropriation of these rights by external interests or local elites (Benjaminsen et al., 2013). There is also potential for financial gain from increased tourism development (Ferraro \& Hanauer, 2014b), although local job creation by wildlife management areas is rare.

It is unlikely that a single explanation accounts for how households benefit from participating in wildlife management areas. We highlight the variability in our observed outcomes, which suggests that the wildlife management area bargain holds potential and that the mechanisms by which households can be affected may vary across contexts.

\section{Insights from village leaders}

Assessments conducted with community leaders and administrators may in part explain why Enduimet and Makame wildlife management areas appear to suffer particularly severe food insecurity, whereas Burunge and Makao are relatively secure. Leaders in the villages of Makao reported the highest earnings from conservation activities, followed by those of Burunge, whereas the two villages in Makame reportedly had yet to receive any revenue from the wildlife management area. Leaders in Makao described benefits from the wildlife management area, such as funding the construction of a secondary school, staffing a village dispensary and facilitating cooperation between the villages, although there was often a lack of consensus on whether revenue was generated by the wildlife management area itself or if funds came from other sources, such as NGOs or tourism companies. Leaders in one of the Makame 
villages agreed that empowering the community to manage and benefit from their natural resources was a gain, but they observed that 'areas for people to graze their livestock are being reduced, [and management has] failed to supervise natural resources efficiently' (Ndedo village leader; interviewed 27 February 2010).

Village assessments revealed that the wildlife management areas, as institutions, varied in their ability to generate revenue and manage resources, following the pattern of observed differences in food insecurity between areas (Fig. 2). The precise reasons, if causality is indeed entailed, are uncertain. The four wildlife management areas vary across ecological gradients, affecting their potential for tourism, although we attempted to control for such variation in our analysis. Differences in revenue may be implicated, although these were reported by the village leaders and may therefore reflect perceived rather than actual earnings. In terms of institutional gains, village leaders in each of the wildlife management areas cited improved management capacity and engagement within and between village governments as positive outcomes of participation, which was suggested in the multi-site report by Tetra Tech \& Maliasili Initiatives (2013). Although these benefits of wildlife management areas are evident at the village level, links to household benefits remain unclear.

On the basis of our findings we recommend that Tanzania's national conservation policy take into account the variability in the performance of wildlife management areas. Some areas may be moderately successful despite disproportionately high levels of human-wildlife conflict, and revenue generation is a likely precursor for mediating any benefits to households. If the wildlife management area programme is to continue, we recommend that implementing agencies think carefully about the specific pathways by which revenues and benefits are transferred from wildlife management areas to participating villages and households, the aspects of livelihoods and well-being that are likely to be affected, how to monitor these outcomes and how they vary between wildlife management areas and villages.

\section{Broader implications}

Variable outcomes of wildlife management areas are not entirely inconsistent with the majority of site-based studies that have shown these areas to be largely ineffective (e.g. Kangalawe \& Noe, 2012; Benjaminsen et al., 2013). It is possible, however, that case studies tend to be conducted in villages with known tensions (Borgerhoff Mulder \& Coppolillo, 2005). Detailed accounts of how projects fail are useful, but generalizations regarding the overall effectiveness of a national-scale strategy should be drawn with care. Our failure to identify consistent positive or negative outcomes of community-based conservation across multiple projects and a fairly broad landscape in Tanzania is consistent with reviews and empirical work globally, which indicate that such outcomes are variable and contextdependent (Garnett et al., 2007; Tallis et al., 2008; Brooks et al., 2012). Thus it is inadvisable to make recommendations regarding policy or implementation on the basis of single case studies. Analyses employing large sample sizes across sites, with multiple controls, are necessary to distinguish outcomes of specific interventions from confounding factors.

We have described the challenges of evaluating community-based conservation. We recommend the use of a meaningful measure of household well-being, sampled across project and control villages, to assess strategy performance in the absence of clearly defined goals and outcomes. However, we acknowledge that comparative data cannot determine causality-how would households in Enduimet and Makame have fared without the wildlife management areas? Studies have shown promise in overcoming this issue of counterfactuals and identifying causal mechanisms of environmental initiatives (reviewed in Ferraro \& Hanauer, 2014a). Although we evaluated our research questions using a controlled analysis and comparatively rich household-level data (Agrawal, 2014), we recognize the need for future research to take a more mechanistic approach to explain the processes underlying our observed outcomes.

In their current form wildlife management areas are not a cure-all for trade-offs between biodiversity and livelihoods in protected-area landscapes in Tanzania. However, our findings indicate that wildlife management areas specifically, and community-based conservation more generally, can be a promising approach as long as policy-makers guide strategies on the basis of evidence of project successes and failures (Tallis et al., 2008), with close attention to variability in project performance (Miteva et al., 2012), and the specific mechanisms through which outcomes are achieved (Agrawal \& Redford, 2006). Evidence for variable outcomes should stimulate research that identifies the best fit between strategy and context, using larger samples of well-controlled data (Borgerhoff Mulder \& Coppolillo, 2005). In the meantime, quantitative research such as ours on the effectiveness of community-based conservation must be comfortable with small effect sizes and substantial variation. Similar approaches applied across the tropics will promote improved strategies and management, and ultimately better conservation outcomes.

\section{Acknowledgements}

We thank Susan James, David Lawson, and the staff and collaborators of Savannas Forever Tanzania. We are grateful to the district and village offices and all interviewees that 
participated in research activities. This paper was significantly improved following comments from two anonymous reviewers.

\section{References}

Agrawal, A. (2014) Matching and mechanisms in protected area and poverty alleviation research. Proceedings of the National Academy of Sciences, 111, 3909-3910.

Agrawal, A. \& Gibson, C.C. (1999) Enchantment and disenchantment: the role of community in natural resource conservation. World Development, 27, 629-649.

Agrawal, A. \& Redford, K.H. (2006) Poverty, Development, and Biodiversity Conservation: Shooting in the Dark? WCS Working Paper No. 26. Wildlife Conservation Society, Washington, DC, USA.

BAIRD, T.D. (2014) Conservation and unscripted development: proximity to park associated with development and financial diversity. Ecology and Society, 19, 4.

BAIRD, T.D. \& LESLIE, P.W. (2013) Conservation as disturbance: upheaval and livelihood diversification near Tarangire National Park, northern Tanzania. Global Environmental Change, 23, 11311141.

Bamford, A.J., Ferrol-Schulte, D. \& Wathan, J. (2014) Human and wildlife usage of a protected area buffer zone in an area of high immigration. Oryx, 48, 504-513.

Barua, M., Bhagwat, S.A. \& Jadhav, S. (2013) The hidden dimensions of human-wildlife conflict: health impacts, opportunity and transaction costs. Biological Conservation, 157, 309-316.

Benjaminsen, T.A., Goldman, M.J., Minwary, M.Y. \& Maganga, F.P. (2013) Wildlife management in Tanzania: state control, rent seeking and community resistance. Development and Change, 44, 1087-1109.

Borgerhoff Mulder, M. \& Coppolillo, P. (2005) Conservation: Linking Ecology, Economics, and Culture. Princeton University Press, Princeton, USA.

Borgerhoff Mulder, M., Hartwig, K., James, S., Levison, D., Ngadaya, E., Packer, C \& Ritter, J.A. (2010) The Whole Village Project: A Platform for Evaluating Rural Development Projects. Http://wholevillage.umn.edu/documents/Evaluation.pdf [accessed 18 May 2015].

Bottrill, M., Cheng, S., Garside, R., Wongbusarakum, S., Roe, D., Holland, M.B. et al. (2014) What are the impacts of nature conservation interventions on human well-being: a systematic map protocol. Environmental Evidence, 3, 16.

Brooks, J.S., Franzen, M.A., Holmes, C.M., Grote, M.N. \& Borgerhoff Mulder, M. (2006) Testing hypotheses for the success of different conservation strategies. Conservation Biology, 20, 1528-1538.

Brooks, J.S., Waylen, K.A. \& Borgerhoff Mulder, M. (2012) How national context, project design, and local community characteristics influence success in community-based conservation projects. Proceedings of the National Academy of Sciences, 109, 21265-21270.

Coad, L., Campbell, A., Miles, L. \& Humphries, K. (2008) The Costs and Benefits of Protected Areas for Local Livelihoods: A Review of the Current Literature. UNEP World Conservation Monitoring Centre, Cambridge, UK.

Coates, J., Swindale, A. \& Bilinsky, P. (2007) Household Food Insecurity Access Scale (HFIAS) for Measurement of Food Access: Indicator Guide. Food and Nutrition Technical Assistance Project, FHI 360, Washington, DC, USA.
Dickman, A.J., Macdonald, E.A. \& Macdonald, D.W. (2011) A review of financial instruments to pay for predator conservation and encourage human-carnivore coexistence. Proceedings of the National Academy of Sciences, 108, 13937-13944.

Doss, C., McPeak, J. \& Barrett, C.B. (2008) Interpersonal, intertemporal and spatial variation in risk perceptions: evidence from East Africa. World Development, 36, 1453-1468.

Ellis, F. \& Mdoe, N. (2003) Livelihoods and rural poverty reduction in Tanzania. World Development, 31, 1367-1384.

Ferraro, P.J. \& Hanauer, M.M. (2014a) Advances in measuring the environmental and social impacts of environmental programs. Annual Review of Environment and Resources, 39, 495-517.

Ferraro, P.J. \& Hanauer, M.M. (2014b) Quantifying causal mechanisms to determine how protected areas affect poverty through changes in ecosystem services and infrastructure. Proceedings of the National Academy of Sciences, 111, 4332-4337.

Garnett, S.T., Sayer, J. \& du Toit, J. (2007) Improving the effectiveness of interventions to balance conservation and development: a conceptual framework. Ecology and Society, 12, 2.

Gelfand, A.E. (1996) Model determination using sampling-based methods. In Markov Chain Monte Carlo in Practice (eds W.R. Gilks, S. Richardson \& D.J. Spiegelhalter), pp. 145-162. Chapman \& Hall, London, UK.

Gillingham, S. \& Lee, P.C. (2003) People and protected areas: a study of local perceptions of wildlife crop-damage conflict in an area bordering the Selous Game Reserve, Tanzania. Oryx, 37, 316-325.

Goldman, M.J. \& Riosmena, F. (2013) Adaptive capacity in Tanzanian Maasailand: changing strategies to cope with drought in fragmented landscapes. Global Environmental Change, 23, 588-597.

Government of Tanzania (2012) The Wildife Conservation (Wildlife Management Areas) Regulations. Ministry of Natural Resources and Tourism, Dar es Salaam, Tanzania.

Hadley, C., Mulder, M.B. \& Fitzherbert, E. (2007) Seasonal food insecurity and perceived social support in rural Tanzania. Public Health Nutrition, 10, 544-551.

Hodinott, J. \& Kinsey, B. (2001) Child growth in the time of drought. Oxford Bulletin of Economics and Statistics, 63, 409-436.

Holmern, T., Nyahongo, J. \& Røskaft, E. (2007) Livestock loss caused by predators outside the Serengeti National Park, Tanzania. Biological Conservation, 135, 518-526.

Hulme, D. \& Murphree, M. (eds) (2001) African Wildife and Livelihoods: The Promise and Performance of Community Conservation. James Currey, Oxford, UK.

Igoe, J. \& Croucher, B. (2007) Conservation, commerce, and communities: the story of community-based wildlife management areas in Tanzania's northern tourist circuit. Conservation \& Society, $5,534-561$.

IUCN \& UNEP (2010) The World Database on Protected Areas (WDPA). UNEP-WCMC, Cambridge, UK. Http://www.protected planet.net [accessed 18 May 2015].

Kangalawe, R.Y.M. \& NoE, C. (2012) Biodiversity conservation and poverty alleviation in Namtumbo District, Tanzania. Agriculture, Ecosystems \& Environment, 162, 90-100.

Kaswamila, A., Russell, S. \& McGibbon, M. (2007) Impacts of wildlife on household food security and income in northeastern Tanzania. Human Dimensions of Wildlife, 12, 391-404.

KIss, A. (2004) Is community-based ecotourism a good use of biodiversity conservation funds? Trends in Ecology \& Evolution, 19, 232-237.

Lawson, D.W., Borgerhoff Mulder, M., Ghiselli, M.E., NGadaya, E., NGOWi, B., Mrinanga, S.G.M. et al. (2014) Ethnicity and child health in northern Tanzania: Maasai pastoralists are disadvantaged compared to neighbouring ethnic groups. PLoS ONE, 9(10), e110447. 
Leader-Williams, N., Kayera, J.A. \& Overton, G.L. (eds) (1996) Conmunity-based Conservation in Tanzania. Occasional Paper of the IUCN Species Survival Commission No. 15. IUCN, Cambridge, UK.

Mackenzie, C.A. (2012) Accruing benefit or loss from a protected area: location matters. Ecological Economics, 76, 119-129.

McCullagh, P. \& Nelder, J.A. (1989) Generalized Linear Models. Chapman \& Hall, New York, USA.

McNally, C.G., Uchida, E. \& Gold, A.J. (2011) The effect of a protected area on the tradeoffs between short-run and long-run benefits from mangrove ecosystems. Proceedings of the National Academy of Sciences, 108, 13945-13950.

Miteva, D.A., Pattanayak, S.K. \& Ferraro, P.J. (2012) Evaluation of biodiversity policy instruments: what works and what doesn't? Oxford Review of Economic Policy, 28, 69-92.

Naughton-Treves, L., Holland, M.B. \& Brandon, K. (2005) The role of protected areas in conserving biodiversity and sustaining local livelihoods. Annual Review of Environment and Resources, 30 , 219-252.

Nelson, F. (2010) The politics of natural resource governance in Africa. In Community Rights, Conservation \& Contested Land (ed. F. Nelson), pp. 3-31. Earthscan, London, UK.

Packer, C., Ikanda, D., Kissui, B. \& Kushnir, H. (2005) Lion attacks on humans in Tanzania. Nature, 436, 927-928.

Persha, L. \& Andersson, K. (2014) Elite capture risk and mitigation in decentralized forest governance regimes. Global Environmental Change, 24, 265-276.

Plummer, M. (2003) JAGS: a program for analysis of Bayesian graphical models using Gibbs sampling. In Proceedings of the $3 \mathrm{rd}$ International Workshop on Distributed Statistical Computing (DSC 2003), Vienna, Austria.

Pullin, A.S., Bangpan, M., Dalrymple, S., Dickson, K., Haddaway, N.R., Healey, J.R. et al. (2013) Human well-being impacts of terrestrial protected areas. Environmental Evidence, 2, 19.

RoE, D. (2008) The origins and evolution of the conservation-poverty debate: a review of key literature, events and policy processes. Oryx, 42, 491-503.

Røskaft, E., Mwakatobe, A. \& Nyahongo, J. (2013) Livestock depredation by carnivores in the Serengeti ecosystem, Tanzania. Environment and Natural Resources Research, 3, 46-57.

SAchedina, H. \& Nelson, F. (2010) Protected areas and community incentives in savannah ecosystems: a case study of Tanzania's Maasai Steppe. Oryx, 44, 390-398.

Salafsky, N., Cauley, H., Balachander, G., Cordes, B., Parks, J., Margoluis, C. et al. (2001) A systematic test of an enterprise strategy for community-based biodiversity conservation.

Conservation Biology, 15, 1585-1595.

Salerno, J.D., Borgerhoff Mulder, M. \& Kefauver, S.C. (2014) Human migration, protected areas, and conservation outreach in Tanzania. Conservation Biology, 28, 841-850.

Sekar, N., Weiss, J.M. \& Dobson, A.P. (2014) Willingness-to-pay and the perfect safari: valuation and cultural evaluation of safari package attributes in the Serengeti and Tanzanian Northern Circuit. Ecological Economics, 97, 34-41.

Sulle, E., Lekaita, E. \& Nelson, F. (2011) From Promise to Performance? Wildlife Management Areas in Northern Tanzania. Tanzania Natural Resource Forum, Arusha, Tanzania.

Tallis, H., Kareiva, P., Marvier, M. \& Chang, A. (2008) An ecosystem services framework to support both practical conservation and economic development. Proceedings of the National Academy of Sciences, 105, 9457-9464.

Tetra Tech \& Maliasili Initiatives (2013) Tanzania Wildlife Management Areas Evaluation. Report prepared for USAID, Dar es Salaam, Tanzania.

Thirgood, S., Woodroffe, R. \& Rabinowitz, A. (2005) The impact of human-wildlife conflict on human lives and livelihoods. In People and Wildlife. Conflict or Coexistence? (eds R. Woodroffe, S. Thirgood \& A. Rabinowitz), pp. 13-26. Cambridge University Press, Cambridge, UK.

West, P., Igoe, J. \& Brockington, D. (2006) Parks and peoples: the social impact of protected areas. Annual Review of Anthropology, 35, 251-277.

\section{Biographical sketches}

Jonathan SALERno has worked in East Africa since 2008 and more recently joined a collaborative project in the West African Sahel. In addition to Savannas Forever Tanzania, his research partners include the Wildlife Conservation Society and the Senegalese Meteorological Agency. Monique Borgerhoff Mulder is an evolutionary anthropologist who began working in East Africa in 1980. She co-founded Savannas Forever Tanzania. MAR K GROTE works on modelling and data analysis, and maintains broad interests in evolutionary biology and ecology. MARGHerita GHiselli has worked as an epidemiologist, data manager and field supervisor for a number of health and development projects in East Africa. CRAIG PACKER has conducted research in East Africa since 1972 and has worked in the Serengeti and Ngorongoro Crater since taking over the Serengeti Lion Project in 1978. He has served as a member of the Tanzanian delegation to CITES and co-founded Savannas Forever Tanzania. 